\title{
Fast and Sustainable Determination of Persistent Organic Pollutants from Organic Fertilizer Using Optimized Microwave-Assisted Extraction Method and Gas Chromatography-Mass Spectrometry
}

\author{
Darlan Ferreira Silva, Maria Diva Landgraf, Maria Olímpia Rezende \\ Institute of Chemistry of São Carlos, University of São Paulo, São Paulo, Brazil \\ Email: darlanveggito@hotmail.com, landgraf@iqsc.usp.br, mrezende@iqsc.usp.br
}

Received 16 October 2015; accepted 1 November 2015; published 5 November 2015

Copyright (C) 2015 by authors and OALib.

This work is licensed under the Creative Commons Attribution International License (CC BY). http://creativecommons.org/licenses/by/4.0/

(c) (i) Open Access

\begin{abstract}
A microwave-assisted extraction was optimized for the evaluation of persistent organic pollutants in liquid fertilizer samples. The extraction process was defined by a $2^{3}$ factorial design. The parameters (temperature and sample and solvent volume) were optimized through the response surface methodology (RSM). The data for the study were based on injection of a mix of organochlorine pesticides. In optimized conditions, the microwave-assisted extraction was carried out at $70^{\circ} \mathrm{C}$ for 10 minutes using $10 \mathrm{~mL}$ of sample and $10 \mathrm{~mL}$ of solvent. This study was accomplishment to evaluate the statistical influence of parameters: temperature, solvent volume and sample volume in the microwave-assisted extraction of organochlorine contaminants present in biofertilizer samples obtained from liquid humus and consequently to define the best conditions of process.
\end{abstract}

\section{Keywords}

Microwave-Assisted Extraction, Persistent Organic Pollutants, Organochlorine Pesticides, Biofertilizers

Subject Areas: Analytical Chemistry, Environmental Chemistry

\section{Introduction}

The liquid humus contains nutrients and organic matter that can bring benefits to the soil and consequently serve as an additive in agriculture, increasing the fertility of the soil or contaminating the environment if it is not con- 
trolled [1]. The production of agricultural fertilizers and industrial organic wastes provides an important means of nutrient recovery. The high content of organic matter present in these wastes contributes to the conditioning of the physicochemical properties of the soil, resulting in an increase in agricultural productivity [2].

The Stockholm Convention, together with the United Nations Environment Programme (UNEP), has defined alternatives to manage, reduce or eliminate persistent organic pollutants (POPs), recognizing that these pollutants have toxic properties. They are resistant to degradation, bioaccumulative and transported by air, water and by migratory species through international boundaries and deposited far from their place of release, where they accumulate in terrestrial and aquatic ecosystems [3].

Organochlorine pesticides (DDT, HCB, HCHs etc.) are classified as POPs and are of global concern with respect to contamination and environmental toxicity [4]. They are one of the most important environmental contaminants; when released in the environment, they may persist or resist to degradation and then remain unchanged for long periods. They are used in effective pest control; its resistance to degradation results in universal contamination of water, soil and foods [5]. They are bioaccumulative, i.e., they are resistant to degradation and their wastes accumulate in animals and persist in the environment, rivers, soils, sediments and other living beings, therefore bioaccumulating up along the food chain [6].

The organochlorine pesticides (OCPs) analysis involves the extraction of these compounds from the matrix, which is difficult by the strong interaction between them and the different components of the matrix, in particular of organic matter. Conventional techniques for removing organic contaminants from complex matrices, such as water, soil and sediment, involve a lot of time in the extraction process, pre-concentration, which is a limiting factor of the entire methodology [7].

Chromatographic techniques are considered the best for the determination of OCPs in a wide variety of matrices, but the extraction and pretreatment methods should be considered before the chromatographic determinations. Conventional extraction methods offer efficiency and accurate results are methods relatively time consuming and hazardous to health due to the use of organic solvents and highly expensive when considering using solvents with high purity [6].

The microwave-assisted extraction (MAE) is a technique using polar solvents such as water, to extract target compounds in solid matrices [8]. The extraction method depends on various physical and chemical parameters, such as temperature, polarity and solvent volume of extraction, irradiation time, stirring and amount of sample in the process [9] etc.

The aim of this study was to optimize a methodology for the extraction of persistent organic pollutants, with emphasis on organochlorine pesticides in biofertilizers obtained from liquid humus using microwave-assisted extraction followed by gas chromatography-mass spectrometry determination.

\section{Materials and Methods}

\subsection{Samples}

To the optimization tests, liquid humus samples obtained from the fermentation of agricultural wastes were used. The mixture consisted of $20 \%$ wastes ( $4 \mathrm{~L}$ poultry $+4 \mathrm{~L}$ of orange peel) with $80 \%$ water $(32 \mathrm{~L}$ ), in volume.

\subsection{Reagents and Solutions}

A mix $\left(2000 \mu \mathrm{g} \cdot \mathrm{L}^{-1}\right)$ of reference material $p, p^{\prime}$-DDT, $p, p^{\prime}$-DDE, $p, p^{\prime}$-DDD, lindane, aldrin, heptachlor, chlordane, dieldrin and HCB (hexachlorobenzene) in hexane: toluene (1:1, in volume) was used for testing. From the reference material, there was prepared a stock solution of $200 \mu \mathrm{g} \cdot \mathrm{mL}^{-1}$ in ethyl acetate. Ethyl acetate HPLC grade was supplied by Tedia. Helium (purity: $99.9990 \%$ ) was supplied by White Martins.

\subsection{Chromatographic System}

The chromatographic system used was a GC/MS, Shimadzu, GC2010 Plus, equipped with split/splitless injector and a mass spectrometric detector, Shimadzu, MS-QP 2010 Plus. The capillary column used was a BP-5 capillary column, $30 \mathrm{~m} \times 0.25 \mathrm{~mm}$ i.d. and $1.0 \mu \mathrm{m}$ film thickness (Agilent). Helium at a constant flow rate of 1 $\mathrm{mL} \cdot \mathrm{min}^{-1}$ was used as carrier gas. The injector and detector temperature were $280^{\circ} \mathrm{C}$. Other operational conditions are described in Table 1. The OCPs were quantified by analytical curve constructed with 6 concentration levels in the range of $10-100 \mathrm{mg} \cdot \mathrm{L}^{-1}$ for each reference material. 
Table 1. Gas chromatograph conditions.

\begin{tabular}{cc}
\hline Injection & Splitless (1 min) \\
\hline Injector temperature & $250^{\circ} \mathrm{C}$ \\
Column temperature & $80^{\circ} \mathrm{C}$ \\
Flow & $\mathrm{He}, 1.0 \mathrm{~mL} \cdot \mathrm{min}^{-1}$ \\
& $50^{\circ} \mathrm{C} \cdot \min ^{-1}$ up to $100^{\circ} \mathrm{C}$ \\
Oven temperature program & $+15^{\circ} \mathrm{C} \cdot \min ^{-1}$ up to $230^{\circ} \mathrm{C}(3: 00 \mathrm{~min})$ \\
& $+5^{\circ} \mathrm{C} \cdot \mathrm{min}^{-1}$ up to $270^{\circ} \mathrm{C}$ \\
\hline
\end{tabular}

The spectrometer was operated in full scan mode for determination of retention times of the compounds and in the SIM mode to analyze the samples. The operating conditions of the mass spectrometer are shown in Table 2 .

\subsection{Microwave-Assisted Extraction}

The extraction procedure was performed in a microwave digestion system (SPEEDWAVE FOUR ${ }^{\circledR}$, with Built-in Non-Contact, Temperature and Pressure Measurement, BERGHOF, Germany) with a capacity of 12 vessels of $60 \mathrm{~mL}$ and $1450 \mathrm{~W}$ maximum power. To the optimization tests, they were used liquid humus samples obtained from the fermentation of agricultural wastes (20:80, in volume) with the extraction solvent (ethyl acetate). The extraction temperature ranged from $70^{\circ} \mathrm{C}$ to $110^{\circ} \mathrm{C}$, sample and solvent volumes ranged from 5 to 10 $\mathrm{mL}$, the irradiation times $(10 \mathrm{~min})$, ramp $(5 \mathrm{~min})$ and power $(80 \%-1160 \mathrm{~W})$ were fixed based on previous experiments.

After the extraction step, the vials were cooled until room temperature and then opened. Then, the material was filtered in $45 \mu \mathrm{m}$ filter paper, concentrated under vacuum in rotary evaporator (FIZATOM) at $80^{\circ} \mathrm{C}$ until dryness, reconstituted with $1 \mathrm{~mL}$ of ethyl acetate and placed in a vial for the chromatographic determination. For tests with blanks, the above procedures were followed using the sample without addition of the reference material.

\subsection{Experimental Design and Optimization of Microwave-Assisted Extraction}

The extraction conditions of POPs evaluated in liquid humus samples were optimized based on the analysis of response surface methodology (RSM) of the investigated factors. In this study, the effects of three factors on the response were evaluated using a $2^{3}$ factorial design, 16 experiments in duplicate were randomly performed according to the experimental design. The area for each compound was chosen as response-variable in the optimization process.

A two-way interaction linear model was adjusted to the experimental data based on Equation (1):

$$
\hat{y}=\beta_{0}+\beta_{1} x_{1}+\beta_{2} x_{2}+\beta_{3} x_{3}+\beta_{12} x_{1} x_{2}+\beta_{13} x_{1} x_{3}+\beta_{23} x_{2} x_{3}
$$

where $\hat{y}$ is the predicted value (area for each compound), $\beta$ 's are the model coefficients, and $x_{1}, x_{2}, x_{3}$ the encoded factors: temperature $\left(x_{1}, 70^{\circ} \mathrm{C}-110^{\circ} \mathrm{C}\right)$, sample volume $\left(x_{2}, 5-10 \mathrm{~mL}\right)$ and solvent volume $\left(x_{3}, 5\right.$ $10 \mathrm{~mL}$ ). The ranges used to evaluate the independent variables were selected based on preliminary experiments.

\section{Results and Discussion}

\subsection{Extraction}

Previous experiments in our laboratory, to extract the compound $p, p$ '-DDT in sewage sludge samples evaluated the significance of the parameters: temperature, extraction time, and percentage of acetone in the solvent mixture (ethyl acetate-acetone). Based on this, new parameters were selected for the present study. Then, the solvent chosen to extraction was ethyl acetate and the extraction time for all tests was 10 minutes.

The use of microwave energy in the extraction process generates heat of solvent and consequently of the sample which can suffer degradation or conversion of some compounds by different ways, such as exposure to high temperatures and pressure inside the microwave extraction vessel [5]. To achieve the best extraction condi- 
Table 2. Operating conditions of mass-spectrometer.

\begin{tabular}{|c|c|c|}
\hline Ion source & $220^{\circ} \mathrm{C}$ & \\
\hline Interface temperature & $250^{\circ} \mathrm{C}$ & \\
\hline Operation mode & SIM & \\
\hline Ionization mode & EL & \\
\hline OCPs & Retention time (min) & $\mathrm{m} / \mathrm{z}$ \\
\hline Hexachlorobenzene & 8.83 & 284,286 \\
\hline Lindane & 9.32 & 281,219 \\
\hline Aldrin & 11.85 & 263,261 \\
\hline Heptachlor & 12.98 & $272,274,183,353$ \\
\hline Chlordane & 13.77 & 373,375 \\
\hline Cis-Chlordane & 14.33 & \multirow{2}{*}{373,375} \\
\hline$p, p^{\prime}-\mathrm{DDE}$ & 15.14 & \\
\hline Dieldrin & 15.28 & 79,277 \\
\hline$o, p^{\prime}-\mathrm{DDD}$ & 15.48 & \multirow{3}{*}{$235,165,235,165$} \\
\hline$p, p^{\prime}-\mathrm{DDD}$ & 16.05 & \\
\hline$p, p^{\prime}$-DDT & 17.18 & \\
\hline
\end{tabular}

tions, a factorial design was used. The actual and encoded levels of the independent variables (temperature, sample volume and solvent volume) for each experiment are shown in Table 3.

Table 4 shows the significance of the extraction process. Bold numbers indicates significant factors as identified by the analysis of variance at the $95 \%$ confidence level.

From the calculated results it can be seen that the factor 3 (solvent volume) was the most important for the majority of the investigated analytes (strongly positive) except for the compounds heptachlor and $o, p$ '-DDD. Only to three compounds, the factor 2 (sample volume) influenced the extraction process, and the major significance of this factor is in the compound hexachlorobenzene. The factor 1 (temperature) was significant for most compounds, but the interaction of this one with the other two factors, i.e., the factor interactions $\left(\beta_{12}\right.$ and $\left.\beta_{13}\right)$ had low significance in the process, and the factor interactions $\beta_{12}$ (temperature $\mathrm{x}$ sample volume) has significance in five compounds. The factor interactions $\beta_{13}$ (temperature $\mathrm{x}$ solvent volume) was not significant in the extraction process. The interaction between sample volume $\mathrm{x}$ solvent volume $\left(\beta_{23}\right)$ is what most influences the process, eight of eleven evaluated compounds were significantly influenced. All calculated regression coefficients $\left(\mathrm{R}^{2}\right)$ are in the range 0.99 , indicating a good correlation to quantify and interpret the relationship between the experimental data and the factor effects studied. Equation (2) describes an example of the proposed model for the compound Aldrin.

$$
\hat{y}=42.526+123.88 x_{1}+16.89 x_{2}+69.68 x_{3}+36.94 x_{1} x_{2}-0.09 x_{1} x_{3}+158.26 x_{2} x_{3}
$$

\subsection{Response Surface Plot Analysis}

Response surface graphics are very useful to estimate and to identify the optimal ranges for the two or more factors on the response [10]. In order to determine the optimum ranges of the factors, graphs were plotted using the z-axis (response) against two of the independent variables (temperature, sample volume and solvent volume), maintaining a third one at a fixed value. Figures 1-3 show an example of the main interactions in the process for the compound Aldrin. Similar plots but not identical were obtained for all the other investigated compounds.

Figure 1 shows the interaction between temperature and the sample volume in response. Increasing the temperature from $70^{\circ} \mathrm{C}$ to $110^{\circ} \mathrm{C}$ and increasing the sample volume from 5 to $10 \mathrm{~mL}$, the response value increase. So, best responses are achieved when using $10 \mathrm{~mL}$ of sample at a temperature of $110^{\circ} \mathrm{C}$, using $10 \mathrm{~mL}$ of the extrac- 


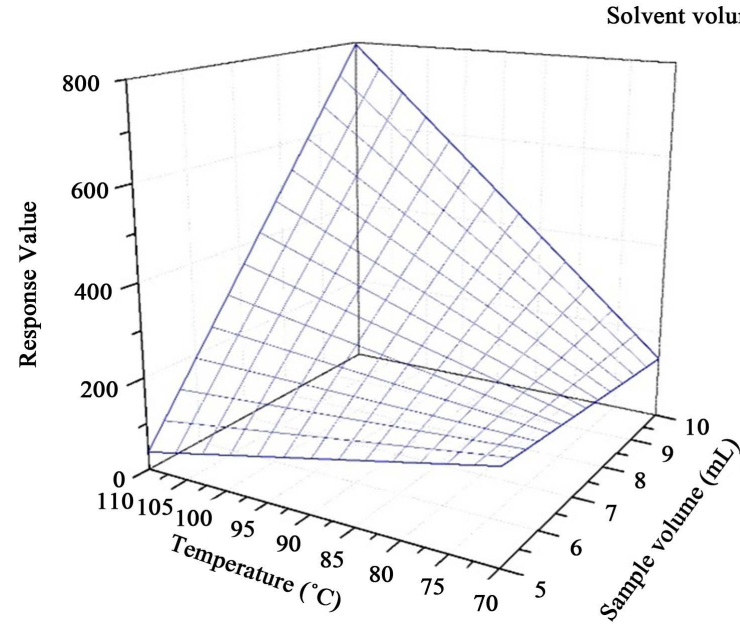

Figure 1. Response surface. Temperature x sample volume.

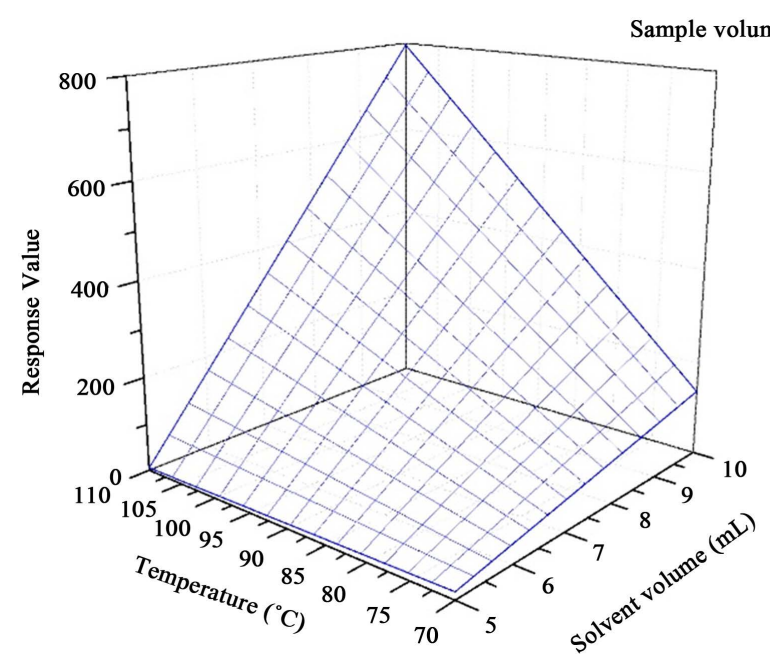

Figure 2. Response surface. Temperature x solvent volume.

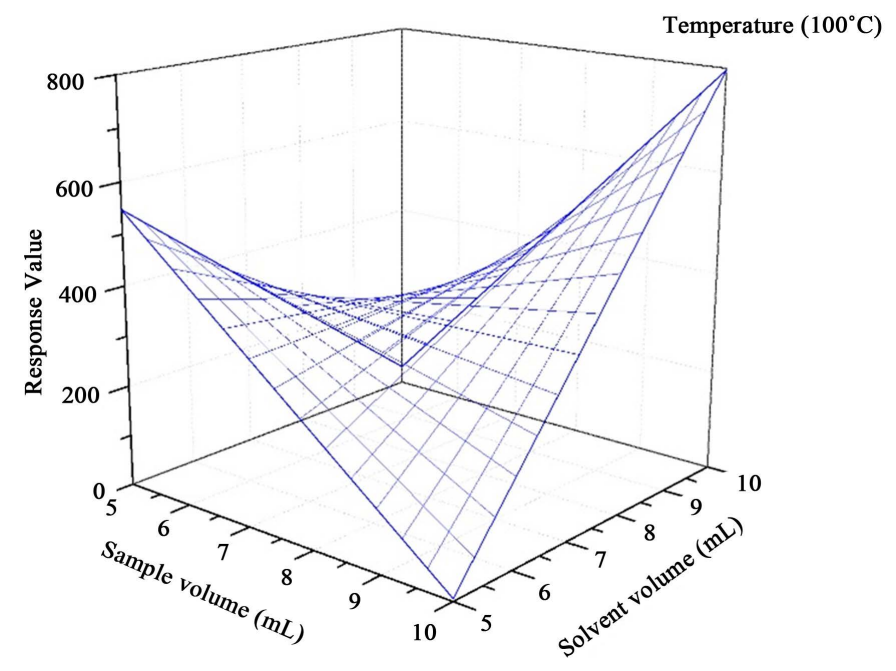

Figure 3. Response surface. Sample volume x solvent volume. 
Table 3. Experimental design $2^{3}$ : actual and encoded levels of the factors.

\begin{tabular}{cccc}
\hline Experiment & Temperature $\left({ }^{\circ} \mathbf{C}\right)$ & Sample volume $(\mathbf{m L})$ & Solvent volume $(\mathbf{m L})$ \\
\hline $\mathbf{1}$ & $70(-)$ & $5(-)$ & $5(-)$ \\
$\mathbf{2}$ & $110(+)$ & $5(-)$ & $5(-)$ \\
$\mathbf{3}$ & $70(-)$ & $10(+)$ & $5(-)$ \\
$\mathbf{4}$ & $110(+)$ & $10(+)$ & $5(-)$ \\
$\mathbf{5}$ & $70(-)$ & $5(-)$ & $10(+)$ \\
$\mathbf{6}$ & $110(+)$ & $5(-)$ & $10(+)$ \\
$\mathbf{7}$ & $70(-)$ & $10(+)$ & $10(+)$ \\
$\mathbf{8}$ & $110(+)$ & $10(+)$ & $10(+)$ \\
\hline
\end{tabular}

\begin{tabular}{cccccccccc}
\multicolumn{7}{c}{ Table 4. Significance levels of parameters (effects) identified by analysis of variance (ANOVA). } \\
\hline & $\boldsymbol{\beta}_{\mathbf{0}}$ & $\boldsymbol{\beta}_{\mathbf{1}}$ & $\boldsymbol{\beta}_{\mathbf{2}}$ & $\boldsymbol{B}_{3}$ & $\boldsymbol{B}_{12}$ & $\boldsymbol{\beta}_{13}$ & $\boldsymbol{B}_{2}$ & $\mathbf{R}^{\mathbf{2}}$ \\
\hline Hexachlorobenzene & 1425.17 & -573.39 & $\mathbf{5 3 1 . 7 7}$ & $\mathbf{1 2 4 6 . 9 9}$ & -491.52 & -1256.93 & $\mathbf{1 4 6 9 . 4 5}$ & 0.9996 \\
Lindane & 1381.15 & -548.96 & -1321.4 & $\mathbf{1 8 2 0 . 2 6}$ & $\mathbf{1 8 1 9 . 3 7}$ & -1198.85 & -564.00 & 0.9982 \\
Aldrin & 220.96 & $\mathbf{2 4 7 . 7 7}$ & $\mathbf{3 3 . 7 8}$ & $\mathbf{1 3 9 . 3 6}$ & $\mathbf{7 3 . 8 8}$ & -0.1875 & $\mathbf{3 1 6 . 5 3}$ & 0.9993 \\
Heptachlor & 235.23 & $\mathbf{3 4 1 . 0 3}$ & -384.0 & -351.67 & -383.10 & -410.48 & $\mathbf{3 5 2 . 3 7}$ & 0.9997 \\
Chlordane & 2356.24 & $\mathbf{1 3 0 3 . 8 9}$ & -400.54 & $\mathbf{4 4 8 . 2 2}$ & -1987.02 & -2684.86 & $\mathbf{3 7 2 0 . 2 0}$ & 0.9981 \\
Cis-Chlordane & 3550.14 & $\mathbf{3 5 7 1 . 3 3}$ & -1612.29 & $\mathbf{1 8 6 . 0 6}$ & -1494.62 & -876.18 & $\mathbf{5 0 6 3 . 6 4}$ & 0.9993 \\
p.p'-DDE & 3472.88 & $\mathbf{1 5 0 4 . 3 0}$ & -1877.10 & $\mathbf{1 5 9 5 . 1 3}$ & $\mathbf{1 7 4 8 . 4 5}$ & -1941.36 & $\mathbf{1 7 4 8 . 5 4}$ & 0.9957 \\
Dieldrin & 2211.94 & -1642.55 & -182.47 & $\mathbf{8 6 4 . 2 2}$ & $\mathbf{1 3 7 8 . 7 9}$ & -862.27 & -1808.21 & 0.9971 \\
o.p'-DDD & 926.99 & $\mathbf{4 9 3 . 0 9}$ & -146.09 & -659.52 & -585.63 & -578.72 & $\mathbf{4 0 3 . 2 2}$ & 0.9991 \\
p.p'-DDD & 1172.76 & -1199.08 & -873.61 & $\mathbf{7 2 0 . 3 4}$ & $\mathbf{9 6 1 . 3 1}$ & -1235.10 & -1373.56 & 0.9999 \\
p.p'-DDT & 85.33 & $\mathbf{- 5 1 . 6 5}$ & $\mathbf{3 5 . 0 4}$ & $\mathbf{4 0 . 3 6}$ & -48.53 & -28.73 & $\mathbf{5 6 . 8 3}$ & 0.9997 \\
\hline
\end{tabular}

tion solvent. Figure 2 shows the interaction between solvent volume with the extraction temperature in response. Increasing the solvent volume from 5 to $10 \mathrm{~mL}$ and increasing the temperature from $70^{\circ} \mathrm{C}$ to $110^{\circ} \mathrm{C}$ the response value increase. Extraction temperature at $110^{\circ} \mathrm{C}$ combined with a solvent volume of $10 \mathrm{~mL}$ provides a better response. Figure 3 shows that best responses are achieved when the maximum sample volume is equal to the maximum solvent volume. The combination of $10 \mathrm{~mL}$ of sample volume, $10 \mathrm{~mL}$ of solvent volume (ethyl acetate) at $110^{\circ} \mathrm{C}$ were considered to provide the best conditions.

Considering the extraction temperature significance in the process, i.e., higher the temperature, higher the yield of the extraction, the chosen temperature was $110^{\circ} \mathrm{C}$. Elevated levels of temperature (above $110^{\circ} \mathrm{C}$ ) would increase the internal pressure inside extraction vessels, which could result in loss of analyte. Thus, the maximum levels of factors sample volume and solvent volume, related to recovery levels, achieved the final extraction conditions were defined, without the need of additional experiments.

\subsection{Recovery Assay: Yield of Extraction}

After defining the best extraction conditions, the recovery of the compounds were evaluated. The recovery assays experiments were performed by adding $125 \mu \mathrm{L}$ of stock solution of $200 \mu \mathrm{g} \cdot \mathrm{mL}^{-1}$ to the extraction vessel, the final volume was $20 \mathrm{~mL}$. Thus, inside of vessels, the concentration of POPs was $1.25 \mu \mathrm{g} \cdot \mathrm{L}^{-1}$. After the extraction procedure, the sample was determined according to the procedure previously described.

Table 5 shows the linear regression, coefficient of determination, average recovery and relative standard deviation of the OCPs studied. 
Table 5. Linear regression, coefficient of determination, recoveries and relative standard deviation of the compounds studied.

\begin{tabular}{ccccc}
\hline Compound & Calibration & $\mathbf{R}^{\mathbf{2}}$ & Average recovery ${ }^{*}$ (\%) & R.S.D $^{*}(\%)$ \\
\hline Hexachlorobenzene & $\mathrm{y}=103.1531 \mathrm{x}+3335.219$ & 0.9930 & $90.66 \pm 1.79$ & 1.82 \\
Lindane & $\mathrm{y}=32.2791 \mathrm{x}+1345.398$ & 0.9876 & $93.07 \pm 0.69$ & 1.19 \\
Aldrin & $\mathrm{y}=75.41816 \mathrm{x}+2372.263$ & 0.9904 & $91.26 \pm 1.07$ & 1.17 \\
Heptachlor & $\mathrm{y}=79.14032 \mathrm{x}+3423.263$ & 0.9903 & $105.68 \pm 3.25$ & 3.08 \\
Clordane & $\mathrm{y}=103.1175 \mathrm{x}+2074.485$ & 0.9935 & $95.40 \pm 2.32$ & 2.43 \\
Cis-Clordane & $\mathrm{y}=84.81596 \mathrm{x}+929.8195$ & 0.9897 & $93.67 \pm 0.90$ & 1.68 \\
$\boldsymbol{p}, \boldsymbol{p}$ '-DDE & $\mathrm{y}=86.3497 \mathrm{x}+1877.259$ & 0.9931 & $97.34 \pm 1.80$ & 1.83 \\
Dieldrin & $\mathrm{y}=71.61183 \mathrm{x}+1392.62$ & 0.9943 & $87.98 \pm 1.02$ & 1.45 \\
$\boldsymbol{o}, \boldsymbol{p}$ '-DDD & $\mathrm{y}=58.34518 \mathrm{x}+8971.62$ & 0.9735 & $97 \pm 2.56$ & 2.27 \\
$\boldsymbol{p}, \boldsymbol{p}$ '-DDD & $\mathrm{y}=91.5611 \mathrm{x}+4521.11$ & 0.9832 & $88.1 \pm 0.82$ & 1.47 \\
$\boldsymbol{p}, \boldsymbol{p}$ '-DDT & $\mathrm{y}=42.1294 \mathrm{x}-1180.484$ & 0.9805 & $100.30 \pm 0.81$ & 0.81 \\
\hline
\end{tabular}

${ }^{*}$ Means \pm standard deviation (duplicate) and relative standard deviation (R.S.D).

In the analysis of blank chromatograms, no peaks related to OCPs were observed. The recoveries values $(87.98 \%-105.68 \%)$ showed that the methodology was suitable for determination of organochlorine pesticide in liquid humus samples.

\section{Conclusions}

Microwave-assisted extraction of organochlorine pesticides from liquid fertilizer samples was satisfactory, considering the recovery percentages obtained (87\% to $105 \%)$ in the determination of 11 organochlorine pesticides. As could be shown, the extraction solvent and the factor interactions between sample volume and solvent volume were the most important and significant during all the experiments. In general, the factor sample volume was not significant and the factor temperature showed a positive effect on the extraction. After a careful analysis of data and combination of them, considering the ranges defined in the experimental design, the optimal extraction conditions were: $10 \mathrm{~mL}$ of sample, $10 \mathrm{~mL}$ of solvent (ethyl acetate) and a temperature of $110^{\circ} \mathrm{C}$.

The production of liquid humus from organic waste increases the aggregated value of this waste, being a good alternative for soil organic matter replacement. However, the quality of the produced organic matter must be attested. Only then, its use becomes environmentally safe.

\section{Acknowledgements}

The authors would like to acknowledge to FAPEMA (Maranhão Foundation for the Protection of Research and Scientific and Technological Development), CNPq (National Council for Scientific and Technological Development), process number 306715/2013-9, FAPESP (São Paulo Research Foundation), process number 2013/13093-7 and NAP 2012-CiTecBio, Provost for Research, University of São Paulo.

\section{References}

[1] Sánchez-Brunete, C., Miguel, E. and Tadeo, J.L. (2008) Determination of Organochlorine Pesticides in Sewage Sludge by Matrix Solid-Phase Dispersion and Gas Chromatography-Mass Spectrometry. Talanta, 74, 1211-1217. http://dx.doi.org/10.1016/j.talanta.2007.08.025

[2] Teixeira, L.S., Vieira, H.P., Windmöller, C.C. and Nascentes, C.C. (2014) Fast Determination of Trace Elements in Organic Fertilizers Using a Cup-Horn Reactor for Ultrasound-Assisted Extraction and Fast Sequential Flame Atomic Absorption Spectrometry. Talanta, 119, 232-239. http://dx.doi.org/10.1016/j.talanta.2013.11.018

[3] Mörner, J., Bos, R. and Fredrix, M. (2002) Reducing and Eliminating the Use of Persistent Organic Pesticides-Guidance 
on Alternative for Sustainable Pest and Vector Management. Inter-Organization Programme for the Sound Management of Chemicals, Geneva.

[4] Tolosa, I., Mesa-Albernas, M. and Alonso-Hernandez, C.M. (2010) Organochlorine Contamination (PCBs, DDTs, HCB, $\mathrm{HCHs}$ ) in Sediments from Cienfuegos Bay, Cuba. Marine Pollution Bulletin, 60, 1619-1624. http://dx.doi.org/10.1016/j.marpolbul.2010.06.008

[5] Barriada-Pereira, M., Concha-Grana, E., González-Castro, M.J., Muniategui-Lorenzo, S., López-Mahía, P., PradaRodríguez, D. and Fernández-Fernández, E. (2003) Microwave-Assisted Extraction versus Soxhlet Extraction in the Analysis of 21 Organochlorine Pesticides in Plants. Journal of Chromatography A, 1008, 115-122.

[6] Li, H.P., Li, G.C. and Jen, J.F. (2003) Determination of Organochlorine Pesticides in Water Using Microwave Assisted Headspace Solid-Phase Microextraction and Gas Chromatography. Journal of Chromatography A, 1012, 129-137. http://dx.doi.org/10.1016/s0021-9673(03)00916-6

[7] Carvalho, P.N., Rodrigues, P.N.R., Alves, F., Evangelista, R., Basto, M.C.P. and Vasconcelos, T.S.D. (2008) An Expeditious Method for the Determination of Organochlorine Pesticides Residues in Estuarine Sediments Using Microwave Assisted Pre-Extraction and Automated Headspace Solid-Phase Microextraction Coupled to Gas Chromatography-Mass Spectrometry. Talanta, 76, 1124-1129. http://dx.doi.org/10.1016/j.talanta.2008.05.035

[8] Ho, W.-H. and Hsienh, S.-J. (2001) Solid Phase Microextraction Associated with Microwave Assisted Extraction of Organochlorine Pesticides in Medicinal Plants. Analytica Chimica Acta, 428, 111-120.

[9] Gfrerer, M. and Lankmayr, E. (2005) Screening Optimization and Validation of Microwave Extraction for the Determination of Persistent Organochloride Pesticides. Analytica Chimica Acta, 533, 203-211. http://dx.doi.org/10.1016/j.aca.2004.11.016

[10] Karabegović, I.T., Stojicević, S.S., Velicković, D.T., Nikolić, N.C. and Lazic, M.L. (2013) Optimization of Microwave-Assisted Extraction and Characterization of Phenolic Compounds in Cherry Laurel (Prunus laurocerasus) Leaves. Separation and Purification Technology, 120, 429-436. http://dx.doi.org/10.1016/j.seppur.2013.10.021 